\title{
IMPLEMENTATION OF A FLEXIBLE LEARNING STUDY PROGRAMME IN A BLENDED-LEARNING DESIGN: RESULTS FROM THE FIRST TWO COHORTS
}

\author{
Claude Müller, Reinhild Fengler, Zurich University of Applied Sciences, Switzerland
}

\begin{abstract}
Zurich University of Applied Sciences (ZHAW) launched the flexible learning study format FLEX, a blended learning design allowing students increased flexibility as to when and where they study. FLEX reduces classroom time by about half, while adding an e-learning environment for self-study that includes instructional videos. An analysis of the first two cohorts in the assessment level showed that the new study format was broadly accepted and that students using the FLEX format achieved exam results equivalent to students in the conventional learning format.
\end{abstract}

\section{Introduction}

Our society is subject to a constant process of transformation, and flexibility plays an increasingly important role in various areas of life. Examples of this include flexible working hours and high availability at work, new family models, and, particularly in the tertiary sector, highly mobile and globalized learners. In this context, more flexibility is expected from universities, and in recent years, flexible learning has come into the focus of pedagogical quality development. Initially established in the USA in the 1970s, interest in flexible learning has steadily developed, which is reflected in an increasing number of publications in this field (Li \& Wong, 2018). Current discussions about the digitalization of education are also strongly influenced by the concept of flexible learning, hence the expressions flexible learning, digital learning, blended learning, and distance learning are often used synonymously.

Flexible learning is a broad term with different interpretations (Boer \& Collis, 2005; Li \& Wong, 2018). In general, flexible learning is intended to meet the diverse needs of learners and enable them to take more responsibility for the learning process (Wade, 1994). Learners and their needs are at the heart of flexible learning, and study programmes should give them the opportunity to make their own decisions regarding how they learn. The British Higher Education Academy describes this concept as "flexible learning is about empowering students by offering them choices in how, what, when and where they learn: the pace, place and mode of delivery" (HEA, 2015; p.1).

From a pedagogical point of view, different dimensions of flexible learning can be identified. According to the frequently quoted article by Chen (2003), flexible learning requires 
flexibility in at least one of the following learning dimensions: time, place, pace, learning style, content, assessment, or learning path. Li and Wong (2018) analysed previous publications and found similar components of flexible learning: time, content, entry requirement, delivery, instructional approach, assessment, resource and support, and orientation and goal. These dimensions provide a framework for orientation with respect to the aspects of flexible learning and offer an opportunity to assess the degree of flexibility of a study program. Nowadays, flexible learning is mainly realized through the use of new technologies (Tucker \& Morris, 2012). However, the dimensions mentioned above show that flexible learning is much more than just the use of new technologies (Li \& Wong, 2018). New technologies, however, serve as important enablers with which flexible learning environments can be designed.

Whether flexible learning leads to equivalent learning outcomes compared with traditional learning approaches has received little attention so far. The current meta-analyses on blended learning (Bernard, Borokhovski, Schmid, Tamim, \& Abrami, 2014; Means, Toyama, Murphy, \& Baki, 2013; Vo, Zhu, \& Diep, 2017) are the best indicators. They find a moderate but significant positive effect of blended learning compared with face-to-face instruction. The problem is that these studies usually do not indicate whether traditional teaching is supplemented by e-learning or replaced. Confounding factors such as additional learning resources, additional learning time, or more/different interactions with the instructor could thus contribute to positive outcomes for blended learning. The authors of the meta-analysis mentioned above concluded that further controlled experimental research is needed to investigate the outcomes of blended learning (Bernard et al., 2014), and that tested design principles must be developed for blended learning (Means et al., 2013).

This paper analyses these issues from a learner's perspective. The following research questions are addressed:

- What are student perceptions of the blended learning format FLEX?

- Does a blended learning design with reduced face-to-face time by half influence the effectiveness of learning?

First, the flexible learning programme FLEX is used as an example to illustrate objectives and considerations when implementing flexible learning in a blended learning design. Then, the research design of the FLEX study program is introduced. Finally, the results are presented and discussed.

\section{Implementation of the FLEX Study Program}

The ZHAW School of Management and Law (SML) launched a new study format for flexible learning (FLEX) in 2015 as part of its comprehensive e-learning strategy. The Bachelor's in Business Administration with a Specialization in Banking and Finance (BSc BA BF), a successful and established programme, was selected as the first to be offered in the FLEX study format. The BSc BA BF is already taught in a full-time (FT) and part-time (PT) format. Accordingly, the FLEX format was the third study format for this degree program. The 
programs have two levels: In the first, the assessment level (first-year studies for full-time students, first three semesters for part-time and FLEX students) worth 60 ECTS (European Credit Transfer System), basic knowledge for the programme is taught. Then in the second section of the programme, 66 ECTS are awarded for the specialization in banking \& finance and 54 ECTS for general business management topics. In the part-time programme, classroom sessions are held on one weekday and a maximum of two evenings and/or Saturday mornings every week during the 14-week semester, while the FLEX format schedules classroom lessons for two days approximately every three weeks during the semester. Fulltime programmes are normally conducted in six semesters, while part-time and FLEX programmes take eight semesters to complete. For part-time studies (including FLEX), a maximum vocational employment level of $60 \%$ is recommended. The concept of the new FLEX study format was developed in 2014 and tested in a business administration course. After a positive evaluation of the pilot module (Müller, Stahl, Alder, \& Müller, 2018), the transformation of a total of 34 courses for the BSc BA BF study programme was conducted. The first cohort of the FLEX study programme will graduate in 2019.

The primary objective of the newly introduced FLEX format is to offer students the best possible opportunity to combine a study program with professional and personal responsibilities. Regarding the number and distribution of face-to-face lessons over the 14week semester, compatibility with a distant place of residence was the guiding principle, e.g., how many overnight stays away from home would be acceptable for potential students. At the same time, regular face-to-face sessions encourage reflection on the course content developed during the online phases. As a result of these considerations, on-site classroom teaching for FLEX was reduced by about half compared with the part-time programme and replaced with online sessions every three weeks. This means that FLEX students attend the campus every three weeks for two days and the interjacent self-study phase allows them to learn flexibly concerning time and place, and to follow their preferred learning path. The selected $49 \%$ faceto-face time corresponds with the current state of empirical knowledge regarding blended learning, namely that with an online ratio of between one third and one half, learning success is higher than for blended learning with a smaller online proportion (Owston \& York, 2018).

After the time structure for the new course of study had been determined, the transition to the flexible learning format was carried out at course level. In so-called scripting workshops, the courses were redesigned according to a defined process using a specially developed didactic visualization language. In the online self-study phase, web-based technologies such as LMS Moodle and other tools are used, and the information is provided in digital form, mainly using learning videos produced in-house. Lecturers create videos for their courses because it is crucial that the content is presented at the appropriate student skill level to enable an exact fit of the self-study phase and the face-to-face phase. A new studio was set up to produce high-quality educational videos, and lecturers receive technical and didactical support. So as not to leave the students alone with an abundance of online learning resources, they are provided with a task plan as guidance for each self-study phase, especially for the assessment 
level of the curriculum. With regard to the dimensions of flexible learning according to Chen (2003), the FLEX format offers greater flexibility in terms of time, place, pace, learning style, and learning path than the conventional study format, but not in terms of assessment and content, which are identical in the FLEX and conventional study formats. As a result, FLEX students take the same examinations at the same time as students in both the full-time and part-time programmes, which allows for a comparison of the exam results with high empirical significance.

\section{Research Design and Methodology}

The research design consists of the first two cohorts of the experimental group FLEX (cohort $15, N=28$; cohort $16, N=28$ ) with students attending all courses in the new FLEX format and the corresponding cohorts of the control group PT (cohort 15, $N=100$; cohort 16, $N=117$ ). All the students were from the first-year intake, and eligibility requirements, lecture content, exam questions, and grading scale were identical for all students in all courses. For the assessment level (the first three semesters), an analysis was conducted to determine how the students evaluated the learning environment and to what extent the results of the end-ofsemester examinations of the experimental and control groups differed from one another. An initial survey was conducted to determine student profiles in order to assess whether deviations in the examination results were primarily due to the learning format or because a cohort was different in some other way. The research design was tightly controlled for a field study in an educational area, firstly because the framework conditions were comparable owing to the same learning objectives and identical assessment and, secondly, because the presence of a control group ensured a quasi-experimental design (see also Fraenkel, Wallen, \& Hyun, 2015).

Analysis of the student profiles in the initial survey showed that most students in the FLEX programme came from the greater Zurich area, with the proportion of students coming from outside being higher in the FLEX programme than in the part-time format. As far as professional employment was concerned, almost all part-time students and all FLEX students were employed, with a high average level of employment of 70\% (PT) and 79\% (FLEX) respectively. Employers tended to support FLEX students by providing a high degree of flexibility in working hours. For example, students were allowed to reduce their working hours during the semester for exam preparation and to work more during the semester breaks. However, no working time could be used for studying. The results concerning the affinity to teamwork were also interesting. FLEX students saw fewer opportunities to learn from others than part-time students and preferred to spend more time learning alone. FLEX students differed significantly from part-time students in terms of teamwork affinity $(p=0.01)$. Regarding ICT literacy, the results showed that both part-time and FLEX students felt secure or very secure when using computers, software, or the Internet. However, FLEX students rated their ICT competence across all items significantly better $(p=0.00)$ than parttime students. 


\section{Results}

\section{Student Perceptions}

At the SML, standardized student evaluations at course level are carried out at the end of each semester, when indicators such as course structure, teaching, or content quality are assessed. With an average of 3.18 across all FLEX fall semester 2015 and 2016 courses (on a 4-level scale, with 4 being the highest value), the global indicator, in which all factors are combined, showed very similar values to PT (3.20). However, at course level, there were considerable variations between the years and study formats. It is, therefore, difficult to assess the acceptance of the new study format based on the results of the student evaluation since yearspecific characteristics (e.g., changes in lecturers) may have a strong influence. Together with the qualitative feedback from FLEX students in both years, however, it can be concluded that students generally accepted the FLEX format.

The survey also proved that the investment in setting up a video studio for the production of short learning videos was perceived as very positive. "Watching learning videos" was described by all students in all FLEX cohorts as the most beneficial activity for learning (see Cohort 15 in Figure 1).

Of course, there are also difficulties in learning in the FLEX format, reflecting problems described in the literature (Samarawickrema, 2005). These lie mainly in self-motivation and also time management: "time management and finding time for self-study" (22_160115), or in the combination of both: "in the beginning, I learned more, and now I postpone it more and more" (18_160215). One student emphasizes the difficulties of the FLEX format with comprehension problems: "Very complex topics are difficult; you can't ask the questions face to face" (17_160216). It seems that offering regular asynchronous and synchronous discussions in forums and online meetings cannot completely replace face-to-face sessions. 


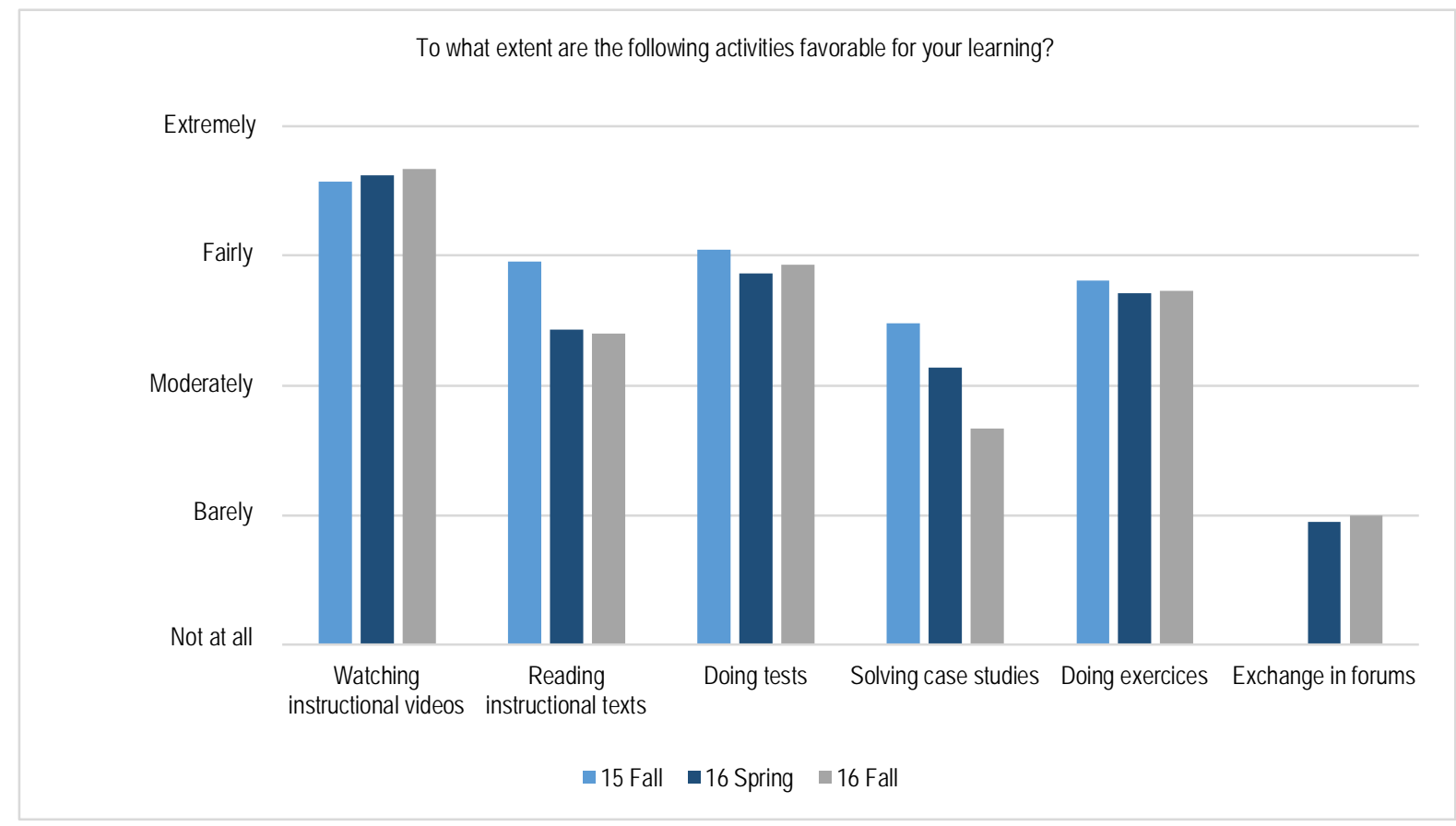

Figure 1. Effectiveness of different learning activities assessed by cohort FLEX $15(n=16)$.

\section{Learning Effectiveness}

The following Tables 1 and 2 list the exam results of Cohort 15 (beginning in Fall Semester 2015) and Cohort 16 (beginning in Fall Semester 2016) for the assessment level (Semesters 13). The exam results of the FLEX students (FLEX) are compared with those of the BF students from the part-time programme (PT). Assessment is identical in all courses and the exams are not corrected by the lecturer of the respective class but by an independent pool of lecturers. In "Business Management Skills" a group project paper is graded by the class teacher. Due to the lower reliability of the assessment, this course is not included in the comparison. The FLEX and PT samples are independent, and the sample size and histograms of the test results do not indicate a violation of the requirements of normal distribution and uniformity of variance.

Table 1: $\quad$ Statistical Analysis of Course Grades FLEX and PT Assessment Level, Cohort 15

\begin{tabular}{lcccccccc}
\hline & \multicolumn{7}{c}{ FLEX format (FLEX) } & \multicolumn{7}{c}{ Part-time format (PT) } \\
Courses (Semester) & $N$ & $M$ & $S D$ & $N$ & $M$ & $S D$ & $d$ & $p$ \\
\hline Business Administration (1) & 27 & 4.24 & 0.53 & 93 & 4.17 & 0.67 & 0.12 & 0.60 \\
Mathematics 1 (1) & 27 & 4.19 & 0.90 & 92 & 4.11 & 0.76 & 0.10 & 0.66 \\
Business Law (1) & 28 & 4.23 & 0.88 & 92 & 4.15 & 0.90 & 0.10 & 0.66 \\
Marketing (1) & 28 & 4.18 & 0.56 & 94 & 4.29 & 0.50 & -0.22 & 0.31 \\
Mathematics 2 (2) & 21 & 4.31 & 0.73 & 81 & 4.23 & 0.83 & 0.09 & 0.71 \\
Business English 1 (2) & 18 & 4.50 & 0.64 & 83 & 4.33 & 0.73 & 0.24 & 0.35 \\
Financial Accounting (2) & 20 & 4.08 & 0.78 & 79 & 4.25 & 0.79 & -0.22 & 0.39 \\
Strategy (3) & 21 & 4.83 & 0.53 & 78 & 4.82 & 0.68 & 0.02 & 0.94 \\
Communication (3) & 20 & 4.20 & 0.66 & 76 & 4.11 & 0.65 & 0.15 & 0.56 \\
Microeconomics (3) & 21 & 3.71 & 0.73 & 74 & 3.74 & 0.76 & -0.04 & 0.88 \\
Business English 2 (3) & 19 & 4.58 & 0.51 & 75 & 4.43 & 0.60 & 0.26 & 0.31 \\
\hline Note: * a 0.05 (two-tailed) & & & & & & & &
\end{tabular}




\section{Implementation of a Flexible Learning Study Programme in a Blended-Learning Design: Results from the First Two Cohorts \\ Claude Müller, Reinhild Fengler}

The results for Cohort 15 (see Table 1) show that the mean values differ only slightly. The direction is indicated by the effect size (Cohen's $d$ ); in 8 of the 11 courses examined, the mean values of the FLEX cohort are higher than those of the PT students (positive sign, range of marks from 1-6, where 6 is the best performance, and all grades below 4 are unsatisfactory). The results of the t-test do not show any significant differences in the exam results between FLEX and PT students. At this point, it should be mentioned that this outcome is not a proof of equivalence. In general, a non-significant result cannot be clear proof of the correctness of a null hypothesis (Schmidt \& Hunter, 1997).

To consider a possible bias at the entry competence level of the first FLEX cohort, the exam results of the second year (Cohort 16) were also analysed (see Table 2). Cohort 16 of the FLEX format also has higher mean values than the control group of PT students (in 8 out of 11 courses). For the three courses "Business Law" $(t(139)=2.23, p=0.028$, with effect size Cohen's $d=0.47)$, "Business English 1" $(t(117)=2.04, p=0.044, d=0.47)$, and "Business English 2" $(t(110)=2.07, p=0.041, d=0.48)$ significant differences can be observed. FLEX students achieved significantly better exam results in these courses compared with PT students.

In summary, it can be concluded that students in the assessment level of the FLEX format achieve exam results equivalent to students in the part-time format.

Table 2: $\quad$ Statistical Analysis of Course Grades FLEX and PT Assessment Level, Cohort 16

\begin{tabular}{lcccccccc}
\hline & \multicolumn{7}{c}{ FLEX format (FLEX) } & \multicolumn{7}{c}{ Part-time format (PT) } & & \\
Courses (Semester) & $N$ & $M$ & $S D$ & $N$ & $M$ & $S D$ & $d$ & $p$ \\
\hline Business Administration (1) & 28 & 4.23 & 0.74 & 117 & 4.25 & 0.70 & -0.03 & 0.89 \\
Mathematics 1 (1) & 28 & 4.04 & 0.82 & 108 & 3.79 & 0.79 & 0.31 & 0.14 \\
Business Law (1) & 28 & 4.34 & 0.72 & 113 & 3.98 & 0.78 & 0.47 & $0.03^{*}$ \\
Marketing (1) & 28 & 4.14 & 0.54 & 110 & 4.20 & 0.67 & -0.09 & 0.68 \\
Mathematics 2 (2) & 23 & 3.98 & 0.70 & 96 & 3.68 & 1.02 & 0.31 & 0.18 \\
Business English 1 (2) & 24 & 4.71 & 0.78 & 95 & 4.31 & 0.87 & 0.47 & $0.04^{*}$ \\
Financial Accounting (2) & 22 & 4.50 & 0.67 & 91 & 4.26 & 0.92 & 0.28 & 0.25 \\
Strategy (3) & 23 & 4.70 & 0.42 & 90 & 4.41 & 0.67 & 0.45 & 0.06 \\
Communication (3) & 22 & 4.14 & 0.47 & 90 & 4.01 & 0.67 & 0.21 & 0.39 \\
Microeconomics (3) & 22 & 4.07 & 0.54 & 87 & 4.08 & 0.97 & -0.01 & 0.95 \\
Business English 2 (3) & 23 & 4.59 & 0.56 & 89 & 4.24 & 0.76 & 0.48 & $0.04^{*}$ \\
\hline
\end{tabular}

Note: ${ }^{*} a=0.05$ (two-tailed)

\section{Discussion}

The ZHAW School of Management and Law is currently transforming an entire study programme into a flexible learning format with the aim of providing more flexibility in terms of time and location. In the blended learning study programme Banking \& Finance FLEX, onsite teaching has been reduced by about half and replaced by three-week online phases. The FLEX results confirm previous findings regarding blended learning (see, e.g., Bernard et al., 2014; Means et al., 2013; Vo et al., 2017) which show that students in blended learning 
courses produce at least equivalent or even slightly better exam results compared with students in face-to-face courses. However, a selection bias in the selection of the study format, i.e., that systematically high-performing students opt for the FLEX programme, cannot be ruled out and must be examined more closely in future research.

Since, in addition to student performance, student satisfaction is also high, it can be concluded that the implementation of the FLEX programme has succeeded in creating an effective learning environment and a satisfactory learning mode for students. This is almost certainly due to the relatively high investment made to meet the requirements of a successful change. Initially, a strategy and vision were formulated, and the transformation was materially and technically supported, including substantial investment in the technical infrastructure.

The FLEX format makes it easier to combine work and study. This is demonstrated by very high employment levels among FLEX students. According to feedback from lecturers and students, this means that learning time and thus the learning activities are concentrated in the time immediately before examinations. FLEX students say they want even more time flexibility in their learning process, i.e., they are provided with as many learning resources as possible without time restrictions or formal conditions and that they can freely decide when they want to learn and with what for optimal exam preparation. Lecturers, on the other hand, have difficulty with this "learning-to-the-test behaviour" and sometimes criticize a lack of commitment to learning and insufficient attendance. Some lecturers would like to have more control, such as being able to set compulsory assignments or tests. Other lecturers view their courses more as a learning opportunity and would like to let students decide how to use it. Therefore, in the future, the presence of students in the face-to-face and online phases should be examined more closely. It needs to be clarified what significance this has for the learning success (Schulmeister, 2017) and how students can be best supported with appropriate incentives and measures (or their combination) to activate learning processes in a flexible study programme.

\section{References}

Bernard, R. M., Borokhovski, E., Schmid, R. F., Tamim, R. M., \& Abrami, P. C. (2014). A meta-analysis of blended learning and technology use in higher education: from the general to the applied. Journal of Computing in Higher Education, 26(1), 87-122. doi:10.1007/s12528-013-9077-3

Boer, W. d., \& Collis, B. (2005). Becoming more systematic about flexible learning: beyond time and distance. ALT-J, 13(1), 33-48. doi:10.1080/0968776042000339781

Chen, D.-T. (2003). Uncovering the provisos behind flexible learning. Educational Technology \& Society, 6(2), 25-30.

Fraenkel, J. R., Wallen, N. E., \& Hyun, H. H. (2015). How to design and evaluate research in education ( $9^{\text {th }}$ ed.). New York: McGraw-Hill. 
HEA (2015). Framework for flexible learning in higher education. Retrieved from https://www.heacademy.ac.uk/system/files/downloads/flexible-learning-in-HE.pdf

Li, K. C., \& Wong, B. Y. Y. (2018). Revisiting the Definitions and Implementation of Flexible Learning. In K. C. Li, K. S. Yuen, \& B. T. M. Wong (Eds.), Innovations in Open and Flexible Education (pp. 3-13). Singapore: Springer Singapore.

Means, B., Toyama, Y., Murphy, R., \& Baki, M. (2013). The Effectiveness of Online and Blended Learning: A Meta-Analysis of the Empirical Literature. Teachers College Record, 115(3), 1-47. Retrieved from http://www.tcrecord.org/Content.asp?ContentId=16882

Müller, C., Stahl, M., Alder, M., \& Müller, M. (2018). Learning Effectiveness and Students' Perceptions in a Flexible Learning Course. European Journal of Open, Distance and Elearning, 21(2), 44-53.

Owston, R., \& York, D. N. (2018). The nagging question when designing blended courses: Does the proportion of time devoted to online activities matter? The Internet and Higher Education, 36(Supplement C), 22-32. https://doi.org/10.1016/j.iheduc.2017.09.001

Samarawickrema, R. G. (2005). Determinants of student readiness for flexible learning: Some preliminary findings. Distance Education, 26(1), 49-66.

Schmidt, F. L., \& Hunter, J. E. (1997). Eight Common but False Objections to Discontinuation of Significance Testing in the Analysis of Research Data. In L. L. Harlow, S. A. Mulaik, \& J. H. Steiger (Eds.), What if there were no significance tests? (pp. 37-64). Mahwah, N.J.: Lawrence Erlbaum Associates Publishers.

Schulmeister, R. (2017). Presence and Self-Study in Blended Learning. eleed, 12(1).

Tucker, R., \& Morris, G. (2012). By Design: Negotiating Flexible Learning in the Built Environment Discipline. Research in Learning Technology, 20(1), n1.

Vo, H. M., Zhu, C., \& Diep, N. A. (2017). The effect of blended learning on student performance at course-level in higher education: A meta-analysis. Studies in Educational Evaluation, 53(Supplement C), 17-28. https://doi.org/10.1016/j.stueduc.2017.01.002

Wade, W. (1994). Introduction. In W. Wade, K. Hodgkinson, A. Smith, \& J. Arfield (Eds.), Flexible Learning in Higher Education (pp. 12-17). Abdington: Routledge. 